\title{
$500 \mathrm{MW}$ 동기발전기용 시뮬레이터 탑재형 디지털 삼중화 여자시스템 개발
}

\section{Development of the Triple Modular Redundant Excitation System with Simulator for 500MW Synchronous Generator}

\author{
류 호 선 ${ }^{*}$ 차 한 주* \\ (Hoseon Ryu $\cdot$ Hanju Cha)
}

\begin{abstract}
TMR(triple modular redundant) digital excitation system with simulator is developed for tuning optimal control parameters during commissioning test and coping with system faults rapidly. A new system which mocks up virtual generator, turbine, grid can simulate as if excitation system is connected to a real generator system by setting four switches. The maintenance crew using the simulator is able to test perfectly the phase controller rectifiers, field breaker, sequence relays as well as TMR controller of the excitation system. Commissioning and performance results about the excitation system with simulator is discussed. The trial product was installed and operated at a 500MW thermal power plant after the commissioning test.
\end{abstract}

Key Words : Real time simulator, Excitation system, Triple modular redundant controller

\section{1. 서 론}

대형 동기발전기용 여자시스템은 발전기 계자전류를 조절 하여 단자전압 및 계통연계시 무효전력을 제어하여 전력계 통 전압안정도에 큰 역할을 담당하고 있다. 이런 중요한 발 전소 주기기인 여자시스템이 예기치 못한 고장으로 인하여 대형 발전소가 불시에 정지되는 사고가 자주발생하고 있다. 발전소의 현장 유지보수원은 복잡한 제어기능과 대전력 위 상제어기로 구성되어 있는 여자시스템의 고장발생시 그 원 인을 신속히 파악할 수 없어서 복구시간이 증대되는 등 많 은 문제점이 발생하고 있다. 발전플랜트의 특성상 많은 노 하우를 가진 제작사 기술자가 방문하여 고장복구를 수행하 고 있으며, 그비용도 상당히 고가로 알려져 있다. 이런 현장 유지 보수원의 고충을 해결하고자 발전기 정지중 디지털 여 자시스템이 마치 계통운전 되는 것처럼 모사할 수 있는 모 의 발전기, 1 기 무한모선 시뮬레이터 내장 여자시스템을 개 발하였다. 현재까지 시뮬레이터 탑재형 여자시스템은 개발 되지 않았으며, 다만 실험실 또는 제작사에서 여자시스템 사 전튜닝 등을 위하여 개인 $\mathrm{PC}$ 로 발전기 시뮬레이터를 제작 하여 소신호(10V이하)로 시험하는 것이 소개되었다[1-4]. 또 한, 24시간 운전하는 발전소의 특수성을 감안하여 운전원과 유지보수원 교육용으로 개발되어 사용된 보고도 있다[5][6]. 최근 전력연구원은 탑재형 시뮬레이터 개발이전에 이동형 외장형 시뮬레이터를 개발하여 상품화하여 수십개의 발전소

† Corresponding Author : Korea Electric Power Company Research Institute

E-mail : hsryu@kepri.re.kr

* Dept. of Electrical Engineering, Chungnam National University, Korea

Received : April 2, 2013; Accepted : September 27, 2013
에 확대적용하였으나, 시험시의 판넬이동 및 여러 케이블 연 결작업이 필요한 단점을 가지고 있었다[7]. 본 논문에서 소 개되는 시뮬레이터는 보드형태로 개발되었으며, 4 개의 별도 의 스위치 동작만으로 마치 발전기 및 터빈이 정상동작하여 현장의 여자시스템 투입조건을 만들어 준다. 그리고 계통연 계 운전도 가상으로 가능하게 할 수 있어서 시운전 또는 고 장 발생시 각종 기능시험을 할 수 있게 되어 있다. 개발된 시뮬레이터 탑재형 여자시스템은 발전기 정지중에 제어기 뿐만 아니라 전력변환부분인 위상제어 정류기, 최종 계자차 단기 시퀀스 등의 모든 시험을 완벽하게 할 수 있다. 시작 품은 2012년 5월에 500MW 표준 석탄화력 발전소에 적용되 어 성능시험이 완벽하게 수행되었고, 현재 상업 운전중에 있 다. 본 논문에서는 시작품의 시뮬레이터 기능과 현장적용시 의 여자시스템 시운전 성능시험에 대한 내용을 상세히 기술 하였다.

\section{2. 본 론}

\section{1 시뮬레이터 탑재형 여자시스템 구성}

시뮬레이터 탑재형 디지털 여자시스템은 삼중화 신호처 리, 제어기, 다중화 위상제어 정류기, 시뮬레이터 모듈 등으 로 구성되어있다. 주제어기는 인벤시스사의 삼중화 제어기 를 사용하였으며, 삼중화 신호처리 보드가 추가로 제작되었 다. 삼중화 신호처리 보드에는 고속의 신호처리연산과 전력 계통안정화(PSS : Power System Stabilizer) 장치의 프로그 램이 내장되어있다. 시스템 구성상 4 개의 스위치동작으로 정상운전과 시뮬레이터 운전으로 전환될 수 있게 설계되었 다. 시뮬레이터 동작시 위상제어 정류기의 건전성도 시험하 기 위하여 정류기 입력단에 $480 \mathrm{~V}$ 를 연결하며, 정류기 출력 
단에 가부하 장치가 구비되어 있어서 싸이리스터가 도통될 수 있도록 하였다. 시뮬레이터는 가부하장치의 전압을 마치 계자전압인 것처럼 인식하게 되어있으며, 시뮬레이터의 모의 $\mathrm{PT}, \mathrm{CT}$ 신호는 다시 삼중화 신호처리보드로 입력되게 스위 치를 설치하였다. 시스템 특성상 정상운전시에는 4 개의 스 위치를 사전조작하는 번거로움은 있지만, 여자시스템 고장 발생 후 누구나 쉽게 시스템에 접근하여 고장부위를 찾을 수 있는 장점을 갖고 있다. 모든 시뮬레이터 조작은 운전원 화면에서 가능하도록 하였다. 시뮬레이터는 크게 발전기, 터 빈 그리고 전력계통이 모델링이 되어있다. 각각의 발전기, 터빈 그리고 전력계통의 상수값은 전력계통에 대한 지식을 갖고 있는 사람이면, 누구나 수정 가능하도록 설계되었다. 특히 대형 발전소의 각종 발전기, 터빈, 전력계통 상수값은 제작사에서 제공하고 있으므로 사전지식이 없더라도 입력데 이터를 발전소와 동일하게 할 수 있다. 가부하장치는 발전 기 계자권선과 흡사하게 하기 위하여 저항과 리액터로 구성 하였으며, 사전튜닝 가능하도록 하였다.

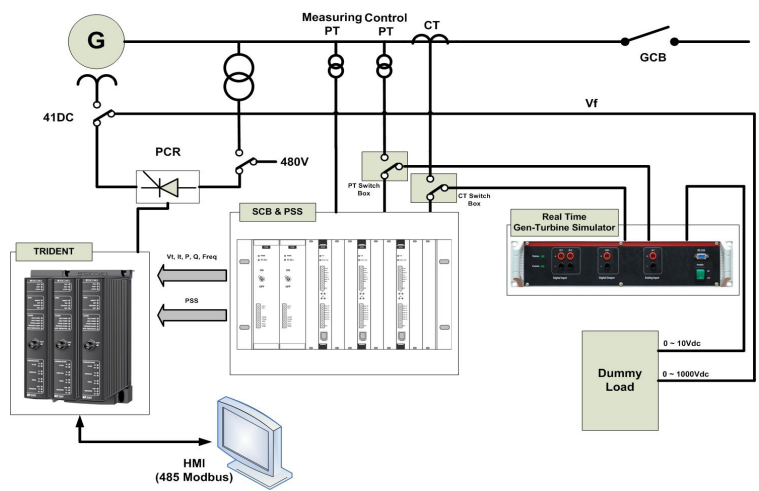

그림 1 시뮬레이터 탑재형 발전기 여자시스템 개략도

Fig. 1 Diagram of the excitation system with simulator for synchronous generator

\section{2 동기발전기 및 1 기무한모선 시뮬레이터}

\subsection{1 동기발전기 모델 및 동적방정식}

동기발전기의 $\mathrm{d}$ 축과 $\mathrm{q}$ 축 등가회로는 그림 2 에서 처럼 IEEE SSFR2 모델을 이용하였다. 팍스 변환(Park's Transformation)식을 이용하여 회전자 권선전류에 의한 회 전자계와 정지된 고정자 권선전류에 의한 회전자계의 전자 기적인 회로관계가 수식화 되어 있다[1]. 발전기 동적 미분 연립방식이 수치해석 알고리즘인 $\mathrm{C} 2 \mathrm{D}$ (Continuous To Discrete)를 이용하여 디지털 시률레이터 보드내에서 이산적 으로 반복하여 계산되고 있다.

$<\mathrm{d}$ 축 방정식 $>$

$$
\begin{aligned}
e_{d}= & -\left(L_{a d}+L_{l}\right) \overline{i_{d}}+L_{a d} \overline{i_{f d}}+L_{a d} \overline{i_{1 d}}+\omega_{r}\left(L_{a q}+L_{l}\right) i_{q} \\
& -\omega_{r} L_{a q} i_{1 q}-\omega_{r} L_{a q} i_{2 q}-R_{a} i_{d} \\
e_{f d}= & -L_{a d} \overline{i_{d}}+\left(L_{a d}+L_{f d}\right) \overline{i_{f d}}+L_{a d} \overline{i_{1 d}}+R_{f d} i_{f d} \\
0= & -L_{a d} \overline{i_{d}}+L_{a d} \overline{i_{f d}}+\left(L_{a d}+L_{1 d}\right) \overline{i_{1 d}}+R_{1 d} i_{1 d}
\end{aligned}
$$

$<\mathrm{q}$ 축 방정식 $>$

$$
\begin{aligned}
e_{q}= & -\left(L_{a q}+L_{l}\right) \overline{i_{q}}+L_{a q} \overline{i_{1 q}}+L_{a q} \overline{i_{2 q}}-\omega_{r}\left(L_{a d}+L_{l}\right) i_{d} \\
& +\omega_{r} L_{a d} i_{f d}+\omega_{r} L_{a d} i_{1 d}-R_{a} i_{q} \\
0= & -L_{a q} \overline{i_{q}}+\left(L_{a q}+L_{1 q}\right) \overline{i_{1 q}}+L_{a q} \overline{i_{2 q}}+R_{1 q} i_{1 q} \\
0= & -L_{a q} \overline{i_{q}}+L_{a q} \overline{i_{1 q}}+\left(L_{a q}+L_{2 q}\right) \overline{i_{2 q}}+R_{2 q} i_{2 q}
\end{aligned}
$$

여기서,

$e_{d}, e_{q}, e_{f d}, i_{d}, i_{q}, i_{f d}: \mathrm{d}$ 축, $\mathrm{q}$ 축 고정자와 계자회로의 전압과 전류 $i_{1 d}, i_{1 q}, i_{2 q}: \mathrm{d}$ 축,q축의 댐퍼회로전류

$L_{a d}, L_{a q}: \mathrm{d}$ 축,q축 상호인덕턴스

$R_{a}, L_{l}$ : 고정자 권선저항, 누설인덕턴스

$R_{1 d}, R_{1 q}, R_{2 q}, L_{1 d}, L_{1 q}, L_{2 q}: \mathrm{d}$ 축, $\mathrm{q}$ 축 댐퍼회로의 저항과 인덕턴스 $R_{f d}, L_{f d}:$ 계자권선저항과 인덕턴스

$\omega_{r}:$ 회전자각속도

또 이때의 회전자의 각속도는 기계적 동적방정식(swing equation)에 의하여 다음과 같이 구할 수 있다.

$$
\begin{gathered}
T_{e}=-\left(L_{a d}+L_{l}\right) i_{d} i_{q}+L_{a d} i_{f d} i_{q}+L_{a d} i_{1 d} i_{q}+\left(L_{a q}+L_{l}\right) i_{q} i_{d} \\
-L_{a q} i_{1 q} i_{d}-L_{a q} i_{2 q} i_{d} \\
{\left[\begin{array}{c}
\dot{\omega}_{r} \\
\dot{\delta}
\end{array}\right]=\left[\begin{array}{cc}
-\frac{K_{D}}{2 H} & 0 \\
120 \pi & 0
\end{array}\right]\left[\begin{array}{c}
\omega_{r} \\
\delta
\end{array}\right]+\left[\begin{array}{cc}
\frac{1}{2 H} & \frac{K_{D}}{2 H} \\
0 & -120 \pi
\end{array}\right]\left[\begin{array}{c}
T_{m}-T_{e} \\
1
\end{array}\right]}
\end{gathered}
$$

여기서,

$\mathrm{H}, \delta_{r}, K_{D}$ : 관성상수, 동기회전 기준좌표로부터 회전자 각위치, 댐핑 계수

$T_{m}, T_{e}, \omega_{0}:$ 기계적토크, 전기적토크, 정격속도

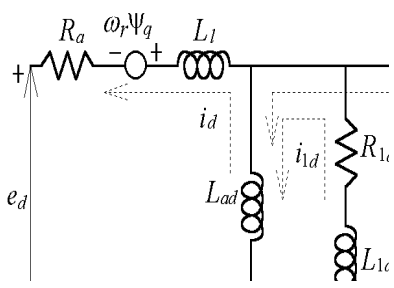

a) d축 등가회로

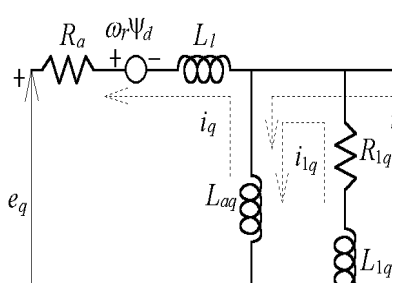

b) q축 등가회로

그림 2 동기발전기 $\mathrm{d}, \mathrm{q}$ 축 등가회로

Fig. $2 \mathrm{~d}, \mathrm{q}$ axis equivalent circuit of synchronous generator

\subsection{2 시뮬레이터 내부블록 다이어그램}

동기발전기, 여자시스템 및 무한계통으로 구성된 전체 시 스템의 블럭도는 그림 3 과 같다. 그림에서 볼 수 있듯이, 스 윙방정식으로부터 각속도의 변화량 $(\Delta \omega)$ 을 입력으로 받은 조속기가 터빈밸브를 조절하면 터빈은 기계적 토크 $\left(\mathrm{T}_{\mathrm{m}}\right)$ 를 출력한다. 동기발전기로부터 단자전압 $\left(\mathrm{E}_{\mathrm{t}}\right)$ 과 단자전류 $\left(\mathrm{I}_{\mathrm{t}}\right)$ 입 력받은 여자시스템은 계자전압 $\left(e_{f d}\right)$ 를 출력한다. 동기발전기 와 무한모선의 결합은 발전기 내부전압을 이용한다. 발전기 전압은 발전기회전자의 $\mathrm{d}, \mathrm{q}$ 축을 기준으로 하였기 때문에, 
무한모선의 입력으로 사용하기 위해서 부하각 $(\delta)$ 를 이용, 시 스템의 $\mathrm{d}, \mathrm{q}$ 축을 기준으로 전류 $i_{D} i_{Q}$ 로 변환한다. 무한모선 계통은 변환된 전류 $i_{D}, i_{Q}$ 를 입력으로 받아서 시스템 $\mathrm{d}, \mathrm{q}$ 축 을 기준으로 한 단자전압 $e_{D} e_{Q}$ 출력으로 내놓는다. 다시 $e_{D}, e_{Q}$ 를 회전자의 $\mathrm{d}, \mathrm{q}$ 축 기준으로 $e_{d}, e_{q}$ 로 변환시키고, 이 전압을 동기발전기에서는 다시 입력으로 사용하게 된다. 동 기발전기는 전류값 $i_{d,} i_{q}$ 와 계자전압 $\left(e_{f d}\right)$ 을 이용하여 새로운 전기적 토크 $\left(\mathrm{T}_{\mathrm{e}}\right)$ 를 발생한다.

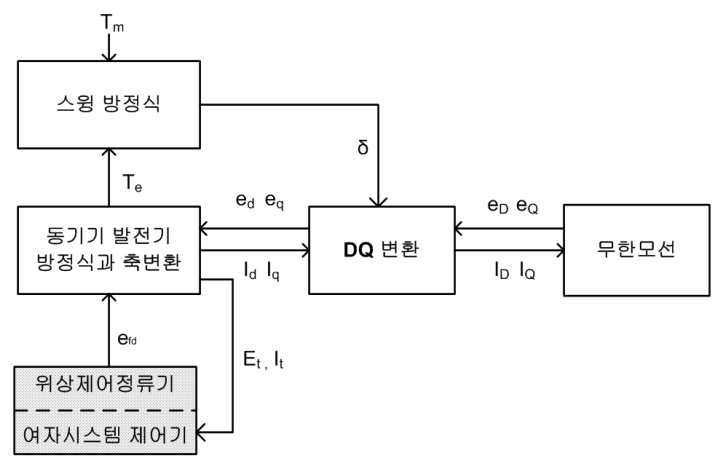

그림 3 실시간보드내 시뮬레이션 흐름도

Fig. 3 Simulation s/w flow of real-time board

1 기 무한모선 계통주파수는 항상 $60 \mathrm{~Hz}$ 라고 가정하였고, 선로의 특성을 무시하고, 로드플로우(load flow)방식으로 접 근하였다. 또 복잡해 보이는 그림 4 를 회로형태로 만든 후, 테브난 정리를 이용하여 테브난 등가회로로 간략화 시켰다 [2]. 먼저 계통회로를 회로화하면 다음과 같다.

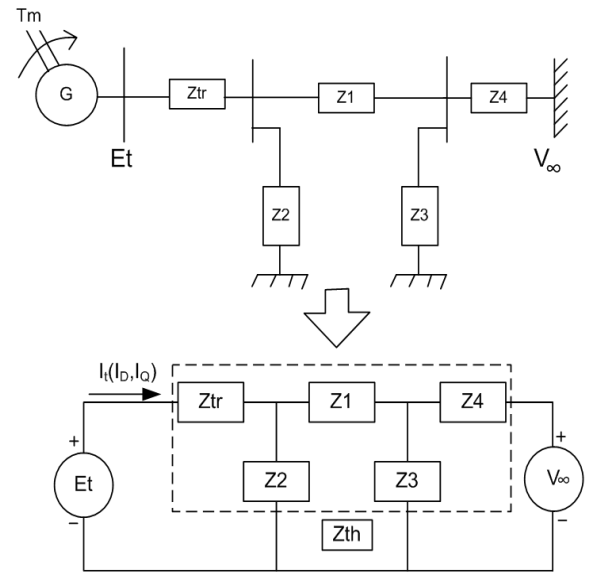

그림 4 간략화된 계통회로도

Fig. 4 Simulation s/w flow of real-time board

$$
\begin{aligned}
Z_{t r} & =R_{t r}+j \omega L_{t r} \\
Z_{1} & =R_{1}+j \omega L_{1} \\
Z_{2} & =R_{2}+j\left(\omega L_{2}-1 / \omega C_{2}\right) \\
Z_{3} & =R_{3}+j\left(\omega L_{3}-1 / \omega C_{3}\right) \\
Z_{4} & =R_{4}+j \omega L_{4} \quad(\text { 단, } \omega=2 \pi f=377=1 \mathrm{pu})
\end{aligned}
$$

여기서,

$Z \mathrm{tr}$ : 발전기측 승압변압기 임피던스,
$\mathrm{Z}_{1}, \mathrm{Z}_{4}$ : 선로 직렬임피던스

$\mathrm{Z} 2, \mathrm{Z}_{3}$ : 선로와 부하의 병렬임피던스

이 회로의 테브난 정리에 의한 등가회로는 다음과 같다.

$$
\begin{aligned}
Z_{t h} & =Z_{t r}+\frac{Z_{2}\left(Z_{1} Z_{3}+Z_{1} Z_{4}+Z_{3} Z_{4}\right)}{Z_{1} Z_{3}+Z_{1} Z_{4}+Z_{2} Z_{3}+Z_{2} Z_{4}+Z_{3} Z_{4}} \\
E_{t} & =Z_{t h} I_{t}\left(I_{D} I_{Q}\right)+V_{\infty}
\end{aligned}
$$

계통시뮬레이션에서는 임피던스 $Z_{1} \sim Z_{4}$ 의 변화로 각종 외란에 대한 모의시험을 실시할 수 있었다.

\subsection{3 실시간 시뮬레이터 보드개발}

모의 동기발전기와 전력계통 실시간 시뮬레이션이 가능한 보드형태 시뮬레이터는 TMS320C33 DSP를 이용하여 개발 하여 모든 제어코드는 $\mathrm{C}$ 와 어셈블러 언어를 이용하여 구현 하였다. 그림 5 에서 나타낸 것처럼 시뮬레이터는 실제 여자 시스템의 출력 직류전압을 받게 되어있고, 그림 3 의 내부 시 뮬레이션 흐름도에서 알 수 있듯이 $60 \mathrm{~Hz} \mathrm{AC} 3$ 상 동기발전 기 전압과 전류를 출력하도록 되어있다. 이때 전압과 전류 의 정확도를 높이기 위하여 다시 출력값 피드백 받아서 $\mathrm{PI}$ 제어기로 오차값을 보상할 수 있게 하였다. 프로그램은 실 시간 $\mathrm{OS}$ 프로그램인 $\mu \mathrm{C} / \mathrm{OS}$ (Micro-C Operation System)를 적용하여 다중작업들(Task)의 특성에 따라서 작업우선권을 주어 불필요한 상호간섭을 막게 하였다. 주요 적용된 작업 은 초기화, 이산 시뮬레이션, 보호, 통신, 진단 등이 수행되 게 하였다.

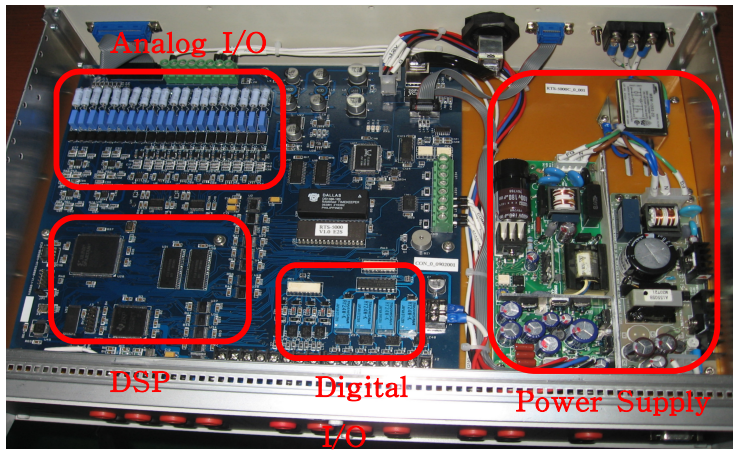

그림 5 시뮬레이터 주제어보드

Fig. 5 Simulator main control board

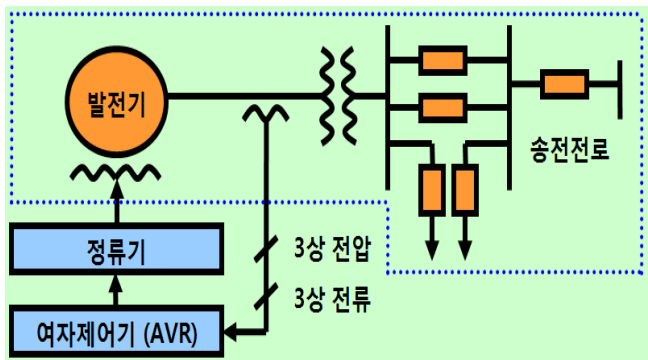

그림 6 시뮬레이터 연결도

Fig. 6 Simulator connection diagram 


\section{3 동기발전기 파라미터를 이용한 시뮬레이션 시험}

개발된 시뮬레이터 탑재형 여자시스템은 실험실에서 철저 한 기능시험을 실시하였다. 표 1 과 표 2 는 현장에 적용된 대상발전소의 발전기 정수들이다. 이 정수들은 시뮬레이터 시험을 위하여 입력되었으며, 계통정수는 별도로 입력되었 다. 그림 7 은 시뮬레이터를 이용한 발전기 부하 스텝시험 파형결과이다. 현장시험과 동일하게 발전기 초기확립 및 정 지시험도 실시되었다. 무부하시험 후 계통연계 운전을 실시 하여 정격부하 운전시 응답특성을 파악하였다. 각종 제어/제 한/보호 튜닝값에 대한 특성시험을 하였고, 최적값을 실제 시스템의 사전 튜닝값으로 설정하였다.

\section{표 $1500 \mathrm{MW}$ 동기발전기 사양}

Table 1 500MW synchronous generator specification

\begin{tabular}{|c|c|c|c|}
\hline 정격전압 & $22,000 \mathrm{~V}$ & 주파수 & $60 \mathrm{~Hz}(3600 \mathrm{rpm})$ \\
\hline 정격출력 & $612 \mathrm{MVA}$ & 계자전압 & $300 \mathrm{~V}$ \\
\hline 계자전류 & $5,224 \mathrm{~A}$ & 계자저항 & $0.0546 @ 75^{\circ} \mathrm{C}$ \\
\hline
\end{tabular}

표 2 동기발전기 파라미터(pu)

Table 2 Synchronous generator parameters(pu)

\begin{tabular}{|c|c|c|c|}
\hline Ra & 0.0466 & R1q & 0.0072 \\
\hline Lad & 1.4353 & L1q & 0.2322 \\
\hline Laq & 1.4044 & R2q & 0.0092 \\
\hline L1 & 0.1470 & L2q & 0.0372 \\
\hline R1d & 0.0086 & Rfd & 0.0075 \\
\hline L1d & 0.0618 & Lfd & 0.0830 \\
\hline
\end{tabular}

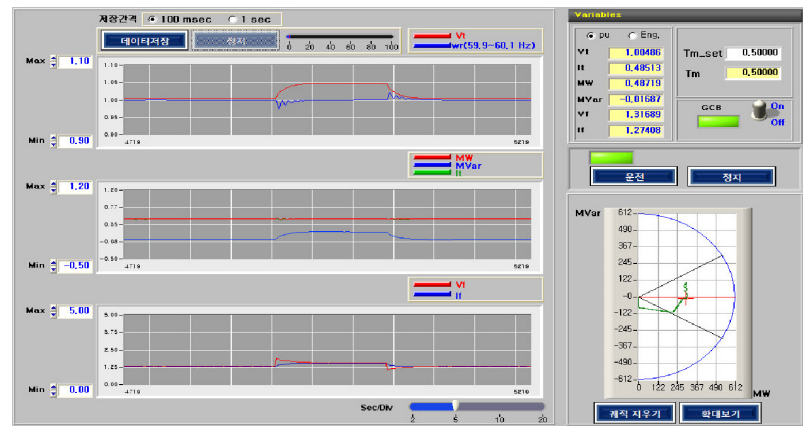

그림 $75 \%$ 스텝응답 시뮬레이션 파형

Fig. 7 5\% step response simulation waveform

\subsection{IEEE 421 모델에 의한 제어블록도 및 튜닝값}

직접여자시스템은 그림 1 에서처럼 발전기 계자권선에 직 류전류를 공급하기 위한 전력원을 직접 발전기출력에서 여 자변압기를 통하여 얻는 시스템을 말한다. 이런 시스템은 응답 속도가 빠른 속응성 시스템을 구성할 수 있어서 최근 모든 발전소에 적용되고 있다. 그림 8 제어블럭도는 IEEE 421 규격에 정의되어 있으며, 각각의 튜닝값은 시운전시 튜 닝을 통하여 최종결정 된다[8]. 본 논문에서는 계산된 튜닝 값을 시뮬레이터를 통하여 그 안정도를 검증하였고, 세부튜
닝 후, 별도의 수정없이 시운전에 사용되었고 시험으로 최종 확인하였다.

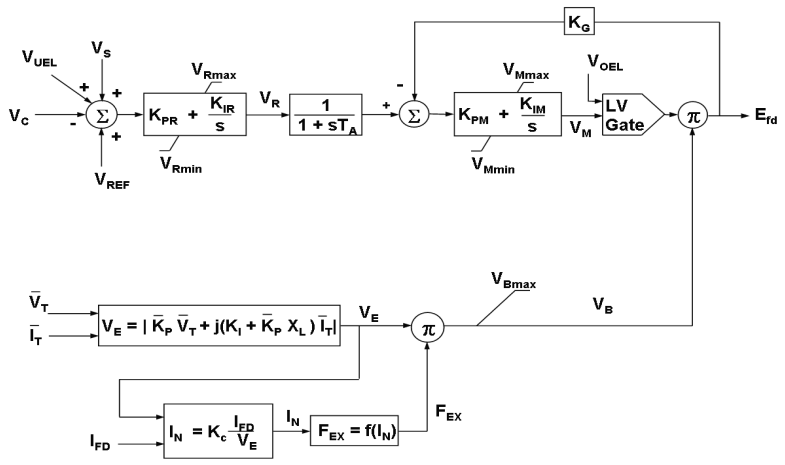

그림 8 IEEE 421-5 ST4B 여자시스템 모델

Fig. 8 IEEE 421-5 ST4B excitation system model

표 3 여자시스템 제어튜닝값

Table 3 Excitation system control parameter tuning values

\begin{tabular}{|c|c|c|c|}
\hline $\mathrm{TR}_{\mathrm{R}}$ & 0.01 & $\mathrm{~K}_{\mathrm{C}}$ & 0.16 \\
\hline $\mathrm{K}_{\mathrm{PR}}$ & 3.0 & $\mathrm{~K}_{\mathrm{IR}}$ & 3.0 \\
\hline $\mathrm{V}_{\mathrm{RMAX}}$ & 0.87 & $\mathrm{~V}_{\mathrm{RMIN}}$ & -0.87 \\
\hline $\mathrm{T}_{\mathrm{A}}$ & 0.01 & $\mathrm{~K}_{\mathrm{G}}$ & 0.0 \\
\hline $\mathrm{K}_{\mathrm{PM}}$ & 1.0 & $\mathrm{~K}_{\mathrm{IM}}$ & 0.0 \\
\hline $\mathrm{V}_{\text {Mmax }}$ & 0.87 & $\mathrm{~V}_{\text {Mmin }}$ & -0.87 \\
\hline $\mathrm{K}_{\text {PM }}$ & 5.4 & $\mathrm{~K}_{\mathrm{IM}}$ & 0.0 \\
\hline $\mathrm{V}_{\text {Bmax }}$ & 6.75 & $\mathrm{X}_{\mathrm{L}}$ & 0.0 \\
\hline
\end{tabular}

여자시스템 전력계통안정화(PSS: Power System Stabilizer) 블럭은 2 개의 입력을 사용하였다. 입력 1 은 발전기 모선의 기계적인 주파수 신호이다. 입력 2 는 $\mathrm{PT}, \mathrm{CT}$ 에서 측정되어 내부에서 계산된 전기적인 전력신호이다. 각각의 신호는 고 주파 필터를 거치는데 속도와 전력의 정상상태 또는 저주파 변화를 제거하여 PSS 출력에 영향이 없도록 하였다. 또한 램프 트랙킹(Ramp tracking) 필터가 사용되었다. 연산된 기 계력 신호를 필터링하도록 설계되었으며, 실제 기계력에 더 욱 가깝도록 저주파 필터링된 출력을 만든다. 램프 트랙킹 이란 말은 경사추적이란 뜻으로서 스텝변화를 필터링하여 급작스런 변화를 완만하게 변화시킨다. 필터는 5 개의 극점 과 1 개의 영점을 갖고 있으며 약 $1.5 \mathrm{~Hz}$ 의 cut-off 주파수를 갖는다. PSS 주요 튜닝값은 $\mathrm{Ks} 1$ 의 이득값이다. 실제 시운전 튜닝시 이득값을 조절하여 응답 특성을 확인하였다. $\mathrm{K}_{\mathrm{s} 1}$ 블 럭후에는 최적위상보상이 필요하여 2단계의 진상-지상블럭 을 사용하였고, 최종단에는 출력값을 제한하는 기능이 있는 데 $-0.05 \sim 0.05 \mathrm{pu}$ 로 세팅하였다.

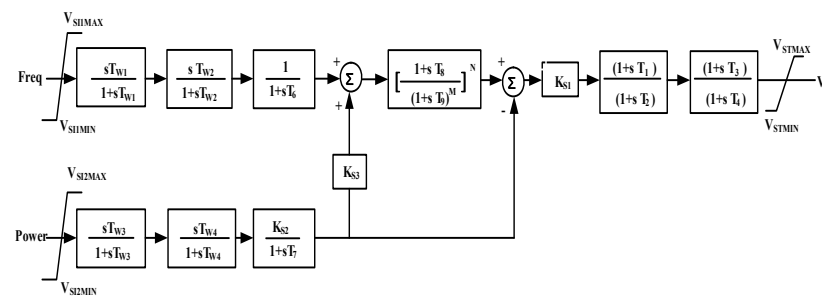

그림 9 IEEE 421-5 dual input PSS2B 모델

Fig. 9 IEEE 421-5 dual input PSS2B model 
표 4 IEEE 421-5 PSS 모델 제어튜닝값

Table 4 IEEE 421-5 PSS model control tuning values

\begin{tabular}{|c|c|c|c|}
\hline Tw1 & 2.0 & Tw2 & 2.0 \\
\hline Tw3 & 2.0 & Tw4 & 0.0 \\
\hline $\mathrm{T}_{6}$ & 0.0 & $\mathrm{~T}_{7}$ & 2.0 \\
\hline $\mathrm{K}_{\mathrm{S} 2}$ & 0.1779 & $\mathrm{~K}_{\mathrm{S3}}$ & 1.0 \\
\hline $\mathrm{T}_{8}$ & 0.5 & T9 & 0.1 \\
\hline $\mathrm{K}_{\mathrm{S} 1}$ & 10 & $\mathrm{~T}_{1}$ & 0.3 \\
\hline $\mathrm{T}_{2}$ & 0.0 & $\mathrm{~T}_{3}$ & 0.0 \\
\hline $\mathrm{T}_{4}$ & 0.0 & $\mathrm{M}, \mathrm{N}$ & 5,1 \\
\hline$V_{\text {StMax }}$ & 0.1 & VSTMIN & 0.0 \\
\hline
\end{tabular}

\section{5 연구시작품 현장설치 후 성능시험}

\subsection{1 무부하 성능시험}

연구시작품은 국내 $500 \mathrm{MW}$ 표준석탄화력 발전소에 설치 되었다. IEEE 421 기준에 의하여 성능시험이 실시되었으며, 각 시운전 단계별 파형이 측정되었다[9]. 그림 10 은 발전기 초기정격전압 확립파형을 나타내고 있다. 초기전압은 정격 전압 $22 \mathrm{kV}$ 까지 소프트 전압확립블록의 기능에 의하여 셋팅 한 값까지 완만하게 상승하는 것을 확인하였다. 발전기전압 초기에 정상적으로 상승하면, 스텝시험을 실시한다. 보통 $\mathrm{IEEE}$ 기준에 의하여 $5 \%$ 스텝신호가 인가되며 큰 오버슈트 없이 안정화되는지 $\mathrm{PID}$ 게인값을 조절하여 최적의 파라미터 값으로 셋팅한다. 발전기 PT 신호문제로 운전을 할 수 없을 경우 여자시스템은 계자전류를 궤환신호로 제어한다. 삼상 위상제어 정류기를 사용하는 여자시스템은 정지시 회전자 (인덕턴스 성분)에 있는 에너지를 입력측으로 회생하는데 그림 10 처럼 정지시에 점호각을 150 도로 하여 계자전압이 (-)값이 되어 전력이 회생되는 것을 알 수 있으며, 이때 발

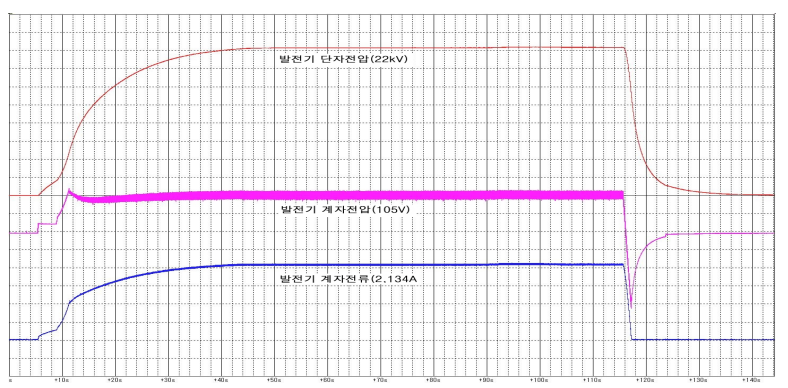

그림 10 초기전압 확립 파형

Fig. 10 Generator voltage build-up waveform

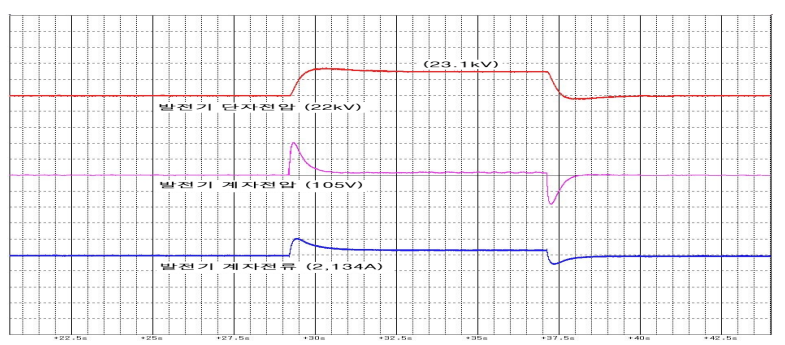

그림 11 발전기전압 5\% 스텝응답 파형

Fig. 11 Generator voltage 5\% step response waveform
전기전압은 빨리 안정적으로 낮아지는 것을 볼 수 있다.

\subsection{2 부하 성능시험}

무부하시험이 정상적으로 끝나면, 전력거래소와의 계약에 의하여 계통병입을 하게 된다. 보통 $500 \mathrm{MW}$ 발전소는 계획 예방정비 후 여러 보호기능을 시험해야 하므로 계통병입을 2-3번 하게 되는데, 이때 여자시스템도 시운전을 병행하여 실시한다. 그림 12 는 발전기 계통병입시점의 파형을 나타내 고 있다. 보통 계통병입 직후 가버너에서는 역전력 계전기 동작을 막기 위하여 정격유효전력의 2-5\% 정도 출력한다. 물론 발전기전압은 계통병입때의 전압을 그대로 유지하며, 운전원은 낮시간 동안 지상무효전력을 공급하기 위하여 전 압을 상승시킨다. 그림 13-14는 발전기 정격 $500 \mathrm{MW}$ 출력 시에 스텝응답시험과 전력계통안정화장치(PSS) 시험을 병행 하여 실시한 파형이다. 전자는 PSS 기능없이 시험을 하였으 며, 이때에 발전기전압 및 기타신호들이 정상적으로 셋팅값 에 응동하는지 확인한다. 후자의 경우 $\mathrm{PSS}$ 의 $\mathrm{Ks} 1$ 의 게인값

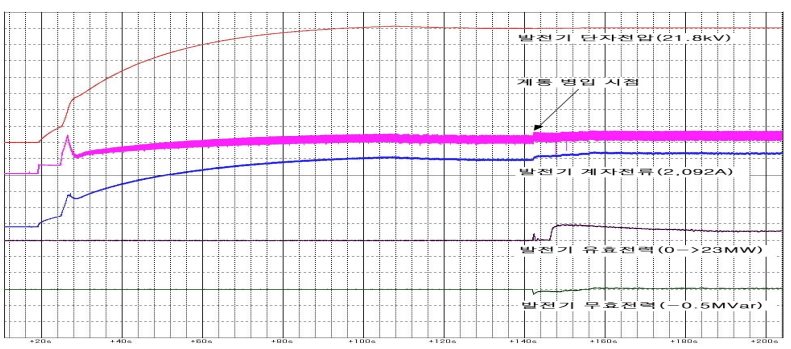

그림 12 발전기 계통병입 파형

Fig. 12 Generator grid connection waveform

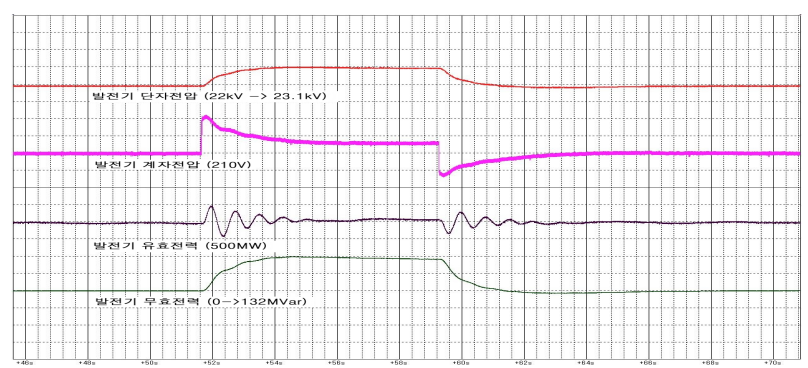

그림 13 전부하운전시 전압 4\% 스텝응답 파형(PSS 미포함)

Fig. 13 Generator voltage 4\% step response waveform during full load (without PSS)

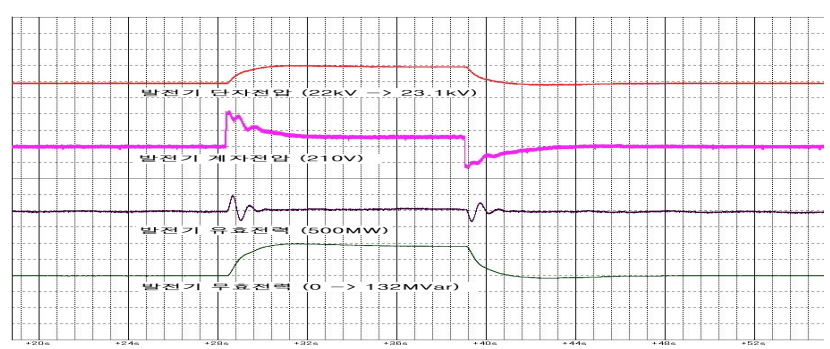

그림 14 전부하운전시 전압 4\% 스텝응답 파형(PSS 포함)

Fig. 14 Generator voltage 4\% step response waveform during full load (with PSS, $K_{s 1}=10$ ) 
을 10 으로 셋팅한 후 시험을 진행하였다. 전자와의 파형을 비교해보면, 유효전력의 과도상태에 따른 댐핑효과가 크게 나타남을 알 수 있다. 물론 게인값을 증가하면, 댐핑효과를 더 크게 볼 수 있으나 게인증가에 따른 발전기 과도안정도 측면에서 10 으로 결정하였다.

\section{6 연구 시작품 외형}

$500 \mathrm{MW}$ 발전소에 적용된 시뮬레이터 탑재형 디지털 삼중 화 여자시스템은 기존의 웨스팅하우스 제품인 WDR-2000 제품을 철거하고 설치되었다. 제어판넬에는 사용자 인터페 이스 TOP (Touch Operation Panel)가 전면에 부착되어 있 고, 내부에는 시뮬레이터, 삼중화 신호처리모듈 그리고 삼중 화 제어기가 위치에 있다. 삼중화 제어기는 내고장성 기능 을 갖고 있어서 2 개의 제어기가 고장이 발생하여도 이상없 이 운전될 수 있다. TOP는 각종 운전화면, $\mathrm{SOE}$ (Sequence Of Event), 실시간 트랜드, 제어변수튜닝 등을 할 수 있도록 설계하였다. 제어신호는 아날로그 4-20mA로 출력이 되어서 위상제어 정류기의 점호모듈에 보내어지며, 총 140 포인트의 $\mathrm{IO}$ 가 사용되었다.

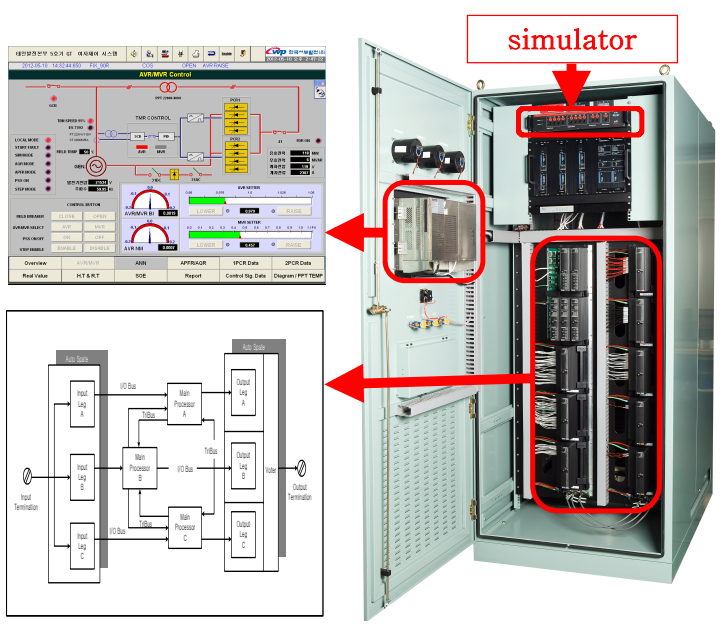

그림 15 현장적용된 여자시스템 제어판넬

Fig. 15 Applied excitation system control pannel

\section{3. 결 론}

$500 \mathrm{MW}$ 대형발전소에 적용된 시뮬레이터 탑재형 디지털 삼중화 여자시스템은 고도의 신뢰성과 설비의 안정성이 요 구되어 IEEE 국제규격에 따라서 성능시험을 실시하였다. 현 장설치 후 각 신호의 건전성 및 제어기능을 발전소 정지중 에 탑재된 발전기-무한모선 디지털 시뮬레이터를 이용하여 시험하였고 제어파라미터를 사전튜닝 하였다. 실제 시운전 시 처음 계획하였던 시운전시간보다 절반가량 빨리 성능시 험을 마칠 수 있어서 발전기 공회전에 따른 과열 및 비용을 절감 할 수 있었다. 본 논문에서 소개된 발전기 무부하 및 부하시험을 통하여 $500 \mathrm{MW}$ 발전기 기준으로 아주 성공적인 성능을 가지고 있음이 확인되었다. 향후 국내외 발전기 여 자시스템에 본 기술을 확대 적용할 예정이며, 대형 발전소의
안정적인 운전에 크게 기여할 것으로 기대된다.

\section{References}

[1] P. Kundur, "Power System Stability and Control" McGraw-Hill Inc., 1994.

[2] Seung-Ill Moon etc, "Development of a new on-line Synchronous Generator Simulator using Personal Computer for Excitation System Studies" IEEE Trans. on Power Systems, 1998.

[3] Joong-Moon Kim and Seung-Il Moon, "A New Optimal AVR Parameter Tuning Method Using On-Line Excitation Control System Model with SQP Method", The trans. of KIEE(A), Vol. 51A, no. 3, 2002.

[4] Joong-Moon Kim, "(A)Study on an AVR parameter tuning method using real-time multi machine power system", Seoul National University, 2003.simulator

[5] P. J. Throckmorton and L. Womiak, " A generic DSP based real-time simulator with application to hydrogenerator speed controller development," IEEE Trans on Energy Conversion, vol. 9, no. 2, June 1994, pp.238-242.

[6] T. J. Overbye, P. W. Sauer, C. M. Marzinzik, and G. Gross, "A user-friendly simulation program for teaching power system operations," IEEE lrans. on Power Systems, vol. IO. no. 4, November 1995, pp.1725-1733.

[7] Joo-Hyun Lee, Ho-Sun Rhew and Tae-Won Jeong, "A Field Test of Diesel Generator Excitation Control System Using Real Time Simulator", The trans. of KIEE, Vol. 59, no. 7, 2010.

[8] IEEE Standard 421.5-1992, IEEE Recommended Practice for Excitation System Models for Power System Stability Studies.

[9] IEEE Std 421.2-1990, IEEE Guide for Identification, Testing, and Evaluation of the Dynamic Performance of Excitation Control Systems.

저 자 소 개

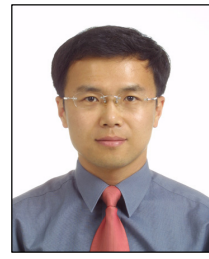

\section{류 호 선 (柳 皓 善)}

1993년 충남대학교 공대 전기공학과 졸 업. 1995년 동 대학원 전기공학과 졸업 (석사). 1995년 현재 한전전력연구원 선 임연구원

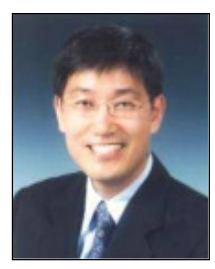

\section{차 한 주 (車 翰 周)}

1988년 서울대학교 전기공학과 졸업. 1990년 포항공대 졸업(석사). 2004년 미 국 Texas A\&M University, College station(공박). 1990년 2001년 LG산전 연구소 책임연구원. 2005년 현재 충남대 전기공학과 교수 